\title{
FATIGUE LIFE ESTIMATION BASED ON CONTINUUM MECHANICS THEORY WITH APPLICATION OF GENETIC ALGORITHM
}

\section{Kamal and M.M. Rahman}

\author{
Faculty of Mechanical Engineering \\ Unviersiti Malaysia Pahang, 26600 Pekan, Pahang, Malaysia \\ Email: mustafizur@ump.edu.my \\ Phone: +6094246239; Fax: +6094246222
}

\begin{abstract}
In recent years research on fatigue estimation methods has focused on developing the capability to handle complex multiaxial loading conditions. The present study presents the development of a new fatigue life estimation model using the concepts of continuum mechanics with a critical plane based approach, where a genetic algorithm is used to estimate the coefficients of the model. Experimental fatigue lives for steel alloy $\mathrm{C} 40$ for in-phase and out-of-phase loading conditions are used to calibrate and analyze the accuracy of the proposed model. Finite element analysis is used to determine the experimental fatigue life of steel alloy $\mathrm{C} 40$ published in literature for validation purposes. The proposed model is simple to apply as it does not need to determine any new material constants or properties for the new model. Fatigue life prediction from the proposed model shows good agreement with experimental results for in-phase and outof-phase multiaxial loading.
\end{abstract}

Keywords: Multiaxial fatigue; genetic algorithm; continuum mechanics; steel C40.

\section{INTRODUCTION}

Since 1860 and Wohler's fatigue investigations, mechanical design has had a major influence on fatigue life determination experiments and predictions [1, 2]. Huge efforts have been made by researchers to safely assess the fatigue life of mechanical components under time-variable loadings [3]. Correctly estimating fatigue life in real components is a complex process having a large number of variables to deal with to avoid unwanted and critical failures [4,5]. The reliability of a fatigue estimation technique depends on its ability to model damage due to non-zero superimposed static stresses, the degree of multiaxiality in the stress field and effects of stress concentration phenomena [6-9]. Fatigue life is difficult to estimate especially in the cases of cyclic or random multiaxial loading conditions, as damage depends on all of the stress components and their variations during the whole time period of load application [6, 10]. To make the results close to reality, the calibration of such an engineering fatigue assessment method should be based on pieces of experimental information that can be easily obtained through tests run in accordance with the pertinent standard codes $[4,6$, 11-13]. The stress analysis is conducted to correctly estimate fatigue damage by directly post-processing simple linear elastic finite element (FE) models [14].

Multiaxial loads, which can be in-phase (proportional) or out-of-phase (nonproportional), are common for many components and structures [15]. Even under uniaxial loads, multiaxial stresses often exist, although typically in-phase, due to 
geometric constraints at notches. Such multiaxial loads and stress states are frequently encountered in many industries, including automotive, aerospace, and power generation, among others [15-17]. Many scientific centers and researchers are dealing with this issue, making new tests and developing models for description of the fatigue phenomena. However, still no universal solution has been found [18]. In this paper a new fatigue life estimation model has been proposed with the capability of handling multiaxial loading conditions.

\section{METHODS AND MATERIALS}

The concept is based on a continuum approach in which theory is formulated by means of evolution equations, i.e., incremental relations and not changes per cycle. The continuum theory contains in itself damage accumulation during arbitrary load histories, proportional or not, and it thereby avoids cycle counting techniques [19]. As mentioned in the literature, if the fatigue life assessment is to be performed under loading conditions close to real loading conditions, long-term histories of a random character are used. Then the application of cycle counting methods leads to an over-complicated lengthy solution, which cannot be applied in practical engineering analysis [20]. A similar approach has been adopted by Brighenti and Carpinteri [4], while developing their endurance function based model, and a dimensionally balanced equation was proposed based on stress invariants. However, in the authors' opinion, because of the use of invariants in their model it ignores information on the direction of crack growth, i.e., the location of the critical plane, which limits the model to be used only in the crack initiation portion of total fatigue life.

To model the evolution equations, previously published models have been studied to identify the parameters required to capture the state of material under load in cases of various material and loading conditions. Strain-based models are considered for this study as they are more robust in capturing high-cycle fatigue and also low-cycle fatigue where plasticity may occur, and the models under study have either gained some degree of acceptance or are representative of a larger group of related models [21]. A model has been proposed based on cyclic shear and normal strain on the plane of maximum shear to define the stress parameter [22, 23] as in Eq. (1). Cyclic shear strains will help to nucleate cracks, and normal strain will assist in their growth.

$$
\frac{\Delta \gamma_{\max }}{2}+S \Delta \varepsilon_{n}=(1.3+0.7 S) \frac{\sigma_{f}^{\prime}-2 \sigma_{n, \text { mean }}}{E}\left(2 N_{f}\right)^{b}+(1.5+0.5 S) \varepsilon_{f}^{\prime}\left(2 N_{f}\right)^{c}
$$

where $\Delta \gamma_{\max }$ is the maximum shear strain range, $\Delta \varepsilon_{\mathrm{n}}$ is the normal strain range on the plane experiencing $\Delta \gamma_{\max }, S$ is a material dependent parameter representing the influence of normal strain on material crack growth, $N_{\mathrm{f}}$ is fatigue life, $\sigma_{\mathrm{f}}{ }^{\prime}, \varepsilon_{\mathrm{f}}{ }^{\prime}, E, b, c$ are material properties having their usual meanings. Building on the work on Brown and Miller [22], Fatemi and Socie [24] proposed to replace the normal strain term by the normal stress, arguing that normal stress can be used to describe mean stress and non-proportional hardening effects (Eq. (2)). Critical plane models that include only strain terms cannot reflect the effect of mean stress or strain path dependent hardening. 


$$
\frac{\Delta \gamma}{2}\left(1+k \frac{\sigma_{n, \max }}{\sigma_{y}}\right)=\frac{\tau_{f}^{\prime}}{G}\left(2 N_{f}\right)^{b \gamma}+\gamma_{f}^{\prime}\left(2 N_{f}\right)^{c \gamma}
$$

where $\Delta \gamma$ is shear strain range, $\sigma_{\mathrm{n}, \max }$ is normal shear stress on the plane from planes having maximum $\Delta \gamma, \mathrm{k}$ is material sensitivity factor, $\sigma_{\mathrm{y}}$ is yield strength,, $\mathrm{N}_{\mathrm{f}}$ is fatigue life, $\tau_{\mathrm{f}}{ }^{\prime}, \gamma_{\mathrm{f}}{ }^{\prime}, \mathrm{G}, \mathrm{b}_{\gamma}, \mathrm{c}_{\gamma}$ are material properties having their usual meanings.

Smith, Watson [25] developed a fatigue model for materials that predominantly fail by crack growth on the planes of maximum tensile strain and stress. The proposed relationship includes both the cyclic strain range and the maximum stress, as in Eq. (3). For multiaxial loading, the SWT parameter is based on the principal strain range $\Delta \varepsilon_{1}$, and maximum stress on the principal strain range plane, $\sigma_{n, \max }$. The stress term is used for describing multiaxial loading and non-proportional hardening effects.

$$
\sigma_{n, \max } \frac{\Delta \varepsilon_{1}}{2}=\frac{\sigma_{f}^{\prime 2}}{E}\left(2 N_{f}\right)^{2 b}+\sigma_{f}^{\prime} \varepsilon_{f}^{\prime}\left(2 N_{f}\right)^{b+c}
$$

Liu [27] presented a virtual strain energy (VSE) model which is a critical plane model, as work quantities are defined for specific planes within the material. For multiaxial loading, VSE considers two possible failure modes: a mode for tensile failure and a mode for shear failure. Failure is expected to occur on the plane having the maximum VSE quantity. $\Delta \mathrm{W}_{\mathrm{I}}$ is computed by first identifying the plane with the maximized axial work and then shear work is added on that same plane, as in Eq. (4). Similarly, $\Delta \mathrm{W}_{\mathrm{II}}$ is computed by first identifying the plane where shear work is maximized and then adding the axial work component as in Eq. (5).

$$
\begin{gathered}
\Delta W_{I}=\left(\Delta \sigma_{n} \Delta \varepsilon_{n}\right)_{\max }+(\Delta \tau \Delta \gamma)=4 \sigma_{f}^{\prime} \varepsilon_{f}^{\prime}\left(2 N_{f}\right)^{p+c}+\frac{4 \sigma_{f}^{\prime 2}}{E}\left(2 N_{f}\right)^{2 b} \\
\Delta W_{I I}=\left(\Delta \sigma_{n} \Delta \varepsilon_{n}\right)+(\Delta \tau \Delta \gamma)_{\text {max }}=4 \tau_{f}^{\prime} \gamma_{f}^{\prime}\left(2 N_{f}\right)^{p \gamma+c \gamma}+\frac{4 \gamma_{f}^{\prime 2}}{G}\left(2 N_{f}\right)^{2 b \gamma}
\end{gathered}
$$

Chu [28] proposed a similar parameter to combine shear and normal work. To include the effects of mean stress, the author replace the stress ranges with maximum stresses, as shown in Eq. (6).

$$
\Delta W=\left(\sigma_{n, \max } \frac{\Delta \varepsilon}{2}+\tau_{n, \max } \frac{\Delta \gamma}{2}\right)_{\max }=1.02 \frac{\sigma_{f}^{\prime 2}}{E}\left(2 N_{f}\right)^{2 b}+1.04 \sigma_{f}^{\prime} \varepsilon_{f}^{\prime}\left(2 N_{f}\right)^{p+c}
$$

From the study of the above models, normal $(\Delta \varepsilon)$ and shear $(\Delta \gamma)$ strain ranges are identified so plasticity induced during the applied loading can be captured. The maximum and mean normal and shear stresses $\left(\sigma_{\max }, \tau_{\max }, \sigma_{\mathrm{m}}, \tau_{\mathrm{m}}\right)$ are selected so that the mean stress effects and material hardening behavior can be included during fatigue life estimation. The developed model is studied for the zero and positive mean, in-phase and out-of-phase tension torsion loading, against experimental fatigue life on a standard notched specimen. 


\section{Proposed Multiaxial Fatigue Models}

Fatigue failure can be considered as the final result of a complex interaction of load and time, where loads may be monotonic, steady, variable, uniaxial or multiaxial [2]. It is characterized by crack nucleation and crack propagation, which can occur in one or more points of the structural component up to the final collapse [4]. Cracks start on the localized shear plane at or near to high stress concentrations, such as persistent slip bands, inclusions, porosity, or discontinuities. The localized shear plane usually occurs at the surface or within grain boundaries. Once nucleation occurs and cyclic loading continues, the crack tends to grow along the plane of maximum shear stress and through the grain boundary [1]. In the present model, material is assumed to be failed as nucleation starts, and a crack is formed and propagates to failure on a characteristic plane known as the critical plane identified as per determined criteria, for example, the plane having the maximum strain or stress range, maximum value of a pre-determined parameter or having maximum variance of shear stress, etc. The proposed evolution equations for the newly proposed model are formulated on a similar pattern to the endurance function model proposed by Brighenti and Carpinteri [4], with one equation defining the damage criteria parameter P, Eq. (7), expressed in terms of strain ranges $(\Delta \gamma$, $\Delta \varepsilon)$, maximum shear and maximum normal stresses $\left(\tau_{\max }, \sigma_{\mathrm{n}, \max }\right)$ determined on the critical plane.

$$
P=a_{1}\left(\Delta \gamma \cdot \tau_{\max }\right)+a_{2}\left(\Delta \varepsilon \cdot \sigma_{n, \max }\right)-\frac{\sigma_{L}^{2}}{E}-e v
$$

where $\mathrm{a}_{1}, \mathrm{a}_{2}$ and $\sigma_{\mathrm{L}}$ are material constants determined by calibrating the model against a known fatigue life and load history.

Parameter $e v$ in Eq. (8) defines the modification of parameter P with stress history. This can be understood with the concept of isotropic and kinematic hardening of materials. The parameter is defined with the criterion that if during a load step $D>0$, then $e v$ is defined by Eq. (8) and if $\mathrm{D}<0$ then $e v$ for that step is zero $(e v=0)$, which means that there is no modification in parameter $\mathrm{P}$ during that load step by $e v$.

$$
e v=V \cdot d P^{m}\left(\frac{\tau_{\max }-\tau_{m}}{E}\right)\left(\frac{\sigma_{\max }-\sigma_{m}}{E}\right)
$$

where $\mathrm{V}$ is the material parameter and $\mathrm{m}$ is the power of the increment of parameter $\mathrm{P}$.

The expression relating damage $\mathrm{D}_{\mathrm{n}}$ for each load step with damage parameter $\mathrm{P}$ and $\Delta \mathrm{P}$, i.e. change in $\mathrm{P}$ with each load step, is shown in Eq. (9), where $\mathrm{K}$ and $\mathrm{R}$ are material parameters.

$$
D_{n}=K \cdot P^{R} . \Delta P
$$

A location most susceptible to fatigue failure is monitored for damage accumulation, the current stress strain state at each load step is evaluated with respect to the mathematical function $\mathrm{P}$ (Eq.(7)) and the stress strain state leading to $\mathrm{P}<0$ is considered as this will not do any damage to the material. In other words, damage increment will occur only when parameter $\mathrm{P}$ for a stress strain state leads to $\mathrm{P}>1$. Also, for damage increment or deterioration to occur, $\Delta \mathrm{P}>0$. The damage $\mathrm{D}$ at the point of the component 
under study is evaluated as the accumulated function of damage increments $D_{n}$ at each load step, so at each load step of the fatigue process, the damage increment is equal to or greater than zero, i.e. $\mathrm{D}_{\mathrm{n}}$, and consequently the material damage $\mathrm{D}$ is a non-decreasing positive function during the load history [19]. Complete damage will occur when D reaches unity $(D=1)$. The logic flow chart of the fatigue life estimation process by the calibrated proposed model is shown in Figure 1.

\section{Model Calibration using Genetic Algorithm}

The proposed model can be used to estimate fatigue life for complex in-phase and outof-phase loading conditions, if all parameters are calibrated according to a known loads and fatigue life. In the present section, a genetic algorithm (MOGA-II) is used to calibrate the model parameters $\left(a_{1}, a_{2}, \sigma_{L}, V, m, K, R\right)$. GAs have advantages with respect to classical techniques, as they allow us to handle problems with multiple minima and non-convexity properties, thus avoiding numerical instability and missing the global optimum [30]. GAs operate by simulating the natural evolution process of life [31]. These algorithms are used to minimize or maximize an objective function chosen to solve a given problem. This method can be used to optimize the model parameters according to the known loading with the fatigue life for the applied loading $[32,33]$. The advantage of using a GA for the proposed model is that the GA can handle any kind of objective function and can handle large population sets. It uses basic concepts like random number generation, choice, switching and combinations of such generated numbers, to get a new population which performs better than the previous generation [34]. This process is repeated iteratively until the required tolerance is achieved and thus the optimal condition can be achieved [35]. In the present study, the objective function is defined as damage prediction error err, as in Eq. (10):

$$
\text { err }=\mathrm{D}-\mathrm{DFL}
$$

where D is the total cumulative damage after each load step and DFL is the inverse of fatigue life at the known loading which is being used for calibration. The values of the model parameters used for characterization of the damage mechanics approach are now found by minimizing the objective function err using the GA procedure [36].

\section{Finite Element Analysis}

Stress / strain distribution is determined for each set of applied load by performing Finite Element Analysis (FEA) of the specimen geometry which is used in determining the experimental fatigue life of steel alloy $\mathrm{C} 40$ published in the literature [11], shown in Figure 2, with material properties given in Table 1. The finite element model is developed utilizing the ANSYS software with 10-node tetrahedral elements, to better capture the curved surfaces of the specimen geometry [37]. Dense mesh at the notch root is maintained by the sphere of influence technique. A non-linear analysis is performed as plastic properties are also included in material model of $\mathrm{C} 40$. Force and moment loads are applied such that they will generate normal and shear stress at the net area as mentioned in Table 1, in-phase and out-of-phase loading conditions are considered, and the corresponding force and moment and fixed support constraints are applied on the specimen model as shown in Figure 2. Details of the applied loads and respective fatigue life taken from the literature [11] are reported in Table 2. As the notch root is considered 
to be the critical point for crack initiation and to predict the fatigue life as close to the experimental values as possible, the state of stress and strain at the notch root is used in estimation of fatigue life.

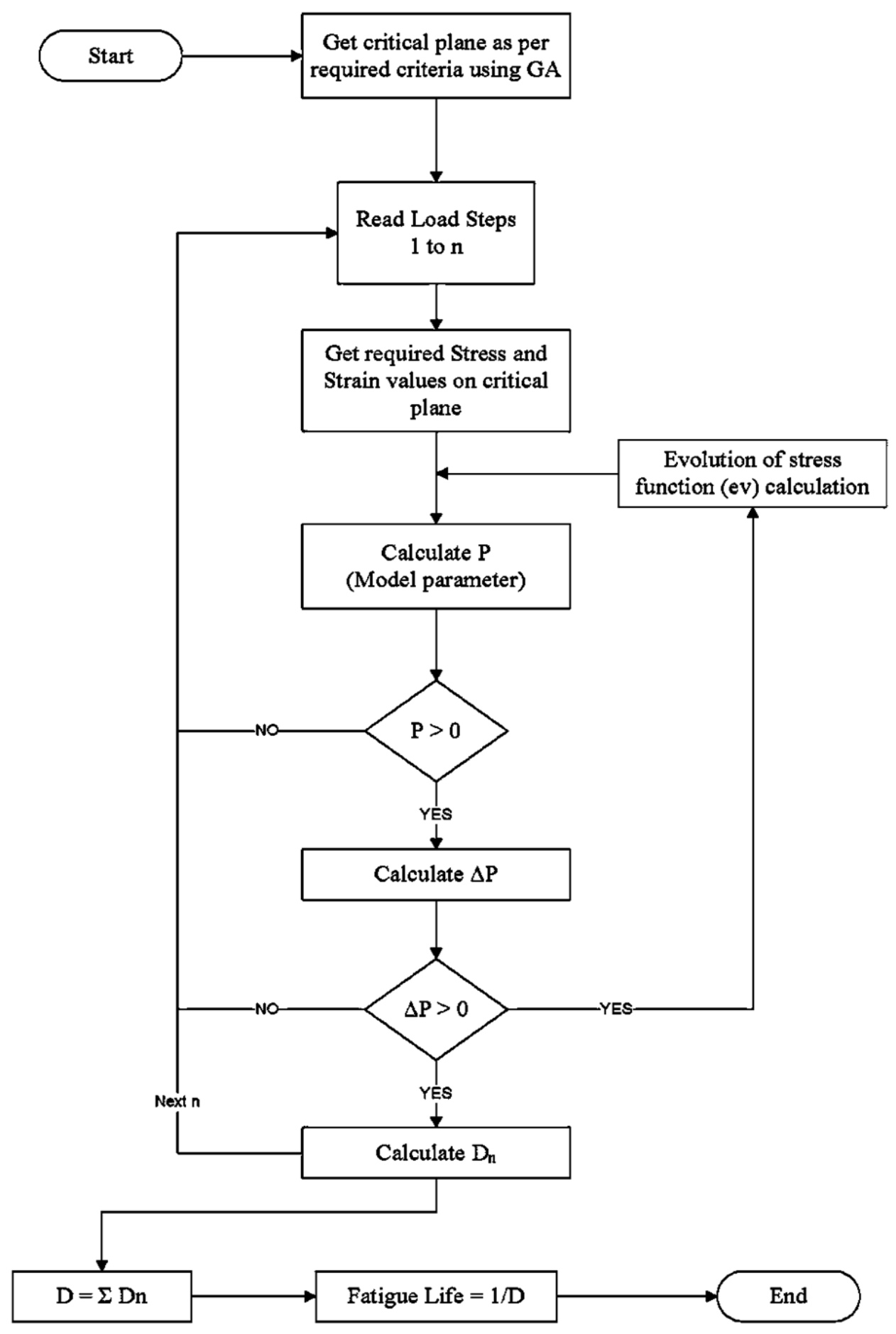

Figure 1. Fatigue life estimation process flow chart for proposed model. 


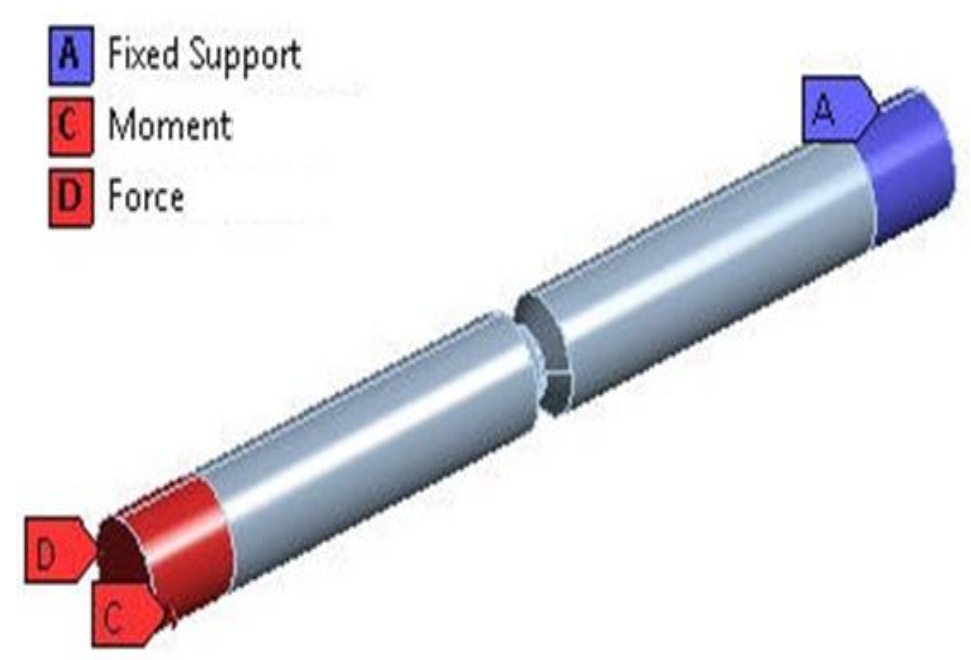

Figure 2. C40 test specimen's FEA model and applied loads on specimen.

Table 1. Mechanical properties of C40 steel.

\begin{tabular}{cccccc}
\hline $\begin{array}{c}\text { Material } \\
\text { name }\end{array}$ & $\begin{array}{c}\text { Young's } \\
\text { Modulus } \\
{[38]}\end{array}$ & $\begin{array}{c}\text { Yield } \\
\text { stress } \\
(\mathrm{MPa})\end{array}$ & $\begin{array}{c}\text { Ultimate tensile } \\
\text { strength }(\mathrm{MPa})\end{array}$ & $\begin{array}{c}\text { Cyclic strain } \\
\text { hardening } \\
\text { exponent, n }\end{array}$ & $\begin{array}{c}\text { Cyclic strength } \\
\text { coefficient, K' } \\
(\mathrm{MPa})\end{array}$ \\
\hline C40a & 206 & 537 & 715 & $0.131 \mathrm{~b}$ & $915 \mathrm{~b}$ \\
\hline \multicolumn{7}{c}{ Source: (a) $[11] ;$} & (b) SAE [39].
\end{tabular}

\section{RESULTS AND DISCUSSION}

A steel alloy C40 specimen (Figure 2) is tested against in-phase and out-of-phase loading conditions published in the literature (Table 2). The proposed model is implemented in ANSYS, by developing an algorithm using Ansys Parametric Design Language (APDL). The algorithm identifies the critical plane by identifying the plane with the maximum value of the critical plane variable crtpl, as in Eq. (11). Normal and shear stress and strain ranges $\left(\sigma_{\mathrm{n}, \max }, \tau_{\max }, \Delta \varepsilon, \Delta \gamma\right)$ with respect to the critical plane are calculated. Now, for calibration loads $\mathrm{CP}_{1}$ and $\mathrm{CP}_{2}$ (Table 2), for each set the calculated stresses and strains are used to determine the model parameters using GA procedures (MOGA-II). The fatigue life value is calculated for the remaining loads other than that used for calibration, using the proposed damage evolution equations, Eqs. (7-9). To implement this, code is developed in APDL which uses the model parameters calculated earlier and estimates fatigue life for the current applied loading.

$$
c r t p l=\left(\Delta \gamma \cdot \tau_{\max }\right)+\left(\Delta \varepsilon \cdot \sigma_{n, \max }\right)
$$

The proposed model is implemented by performing FEA to calculate the stress state at the notch root surface of the specimen, as the notch root is the most susceptible region for failure. Then stress components on the critical plane are calculated and used with Eqs. (7) - [29] and the GA tool to estimate the coefficients of the proposed model to estimate the fatigue life. Two sets of fatigue life are predicted: one with one calibration point $\mathrm{CP}_{1}$ and the second with two calibration points $\mathrm{CP}_{1}$ and $\mathrm{CP}_{2}$ (Table 3), where the 
coefficients for each load step are interpolated between the coefficients of the calibration points.

Table 2. Experimental loads and fatigue life of C-40 specimen having notch radius 0.5 $\mathrm{mm}\left(\sigma_{\mathrm{a}} / \tau_{\mathrm{a}}=1\right)[11]$.

\begin{tabular}{cccc}
\hline $\begin{array}{c}\text { Normal and shear stress } \\
\text { at net area }(\sigma \mathrm{\sigma a}, \tau \mathrm{a})(\mathrm{MPa})\end{array}$ & $\begin{array}{c}\text { Load ratio } \\
(\mathrm{R})\end{array}$ & $\begin{array}{c}\text { Phase } \\
\text { difference }\left(^{\circ}\right)\end{array}$ & $\begin{array}{c}\text { Cycles to failure } \\
\left(\mathrm{N}_{\mathrm{f}}\right) \times 10^{6}\end{array}$ \\
\hline $101_{(\mathrm{CP} 2)}$ & -1 & 0 & 2.0 \\
129.75 & -1 & 0 & 0.18 \\
159.92 & -1 & 0 & 0.072 \\
179 & -1 & 0 & 0.21 \\
$200_{(\mathrm{CP} 1)}$ & -1 & 0 & 0.027 \\
221 & -1 & 0 & 0.012 \\
$99.6_{(\mathrm{CP} 2)}$ & -1 & 90 & 2.0 \\
119.5 & -1 & 90 & 0.94 \\
140 & -1 & 90 & 0.285 \\
160.25 & -1 & 90 & 0.044 \\
180 & -1 & 90 & 0.016 \\
$199.7_{(\mathrm{CP} 1)}$ & -1 & 90 & 0.011 \\
$67.9_{(\mathrm{CP} 2)}$ & 0 & 0 & 2.0 \\
79.72 & 0 & 0 & 0.79 \\
99.56 & 0 & 0 & 0.35 \\
119 & 0 & 0 & 0.157 \\
138.58 & 0 & 0 & 0.0477 \\
$158.1_{(\mathrm{CP} 1)}$ & 0 & 0 & 0.026 \\
$66.8_{(\mathrm{CP} 2)}$ & 0 & 90 & 2.0 \\
89.55 & 0 & 90 & 0.34 \\
119.3 & 0 & 90 & 0.094 \\
138.75 & 0 & 90 & 0.034 \\
$158.1_{(\mathrm{Cp} 1)}$ & 0 & & 0.022 \\
\hline
\end{tabular}

Note: $\mathrm{CP}_{1}$ and $\mathrm{CP}_{2}$ are first and second calibration points for model coefficients determination

Results from experimental fatigue life values from the literature (Table 2) [40] and predictions made by the proposed model with one and two calibration points are reported in Figure 3. The results show that the proposed model predicted results for $\mathrm{R}=-$ 1 (zero mean) load with phase $=0$ with good agreement for the single calibration point $\left(\mathrm{CP}_{1}\right)$ as well as the two calibration point case $\left(\mathrm{CP}_{1} \& \mathrm{CP}_{2}\right)$. The $\mathrm{CP}_{1}$ only case is on the slightly conservative side, but the two-point case follows the experimental fatigue life trend more closely, although slightly on the non-conservative side but in an acceptable range, and can be considered as predicting the fatigue behavior with acceptable accuracy. Similarly, for $\mathrm{R}=-1$ (zero mean) load with phase $=90$, with the $\mathrm{CP}_{1}$ only case the results are increasingly on the conservative side as we move away from the calibration point load. But for the two-point $\mathrm{CP}_{1} \& \mathrm{CP}_{2}$ case, the predicted fatigue life agreed well with the experimental fatigue life. From this we see the effectiveness of using more than one calibration point and the results are found to be on the conservative side but in range to 
be declared as in good agreement with the experimental life. Brighenti, Carpinteri [41] also reported that for different materials the endurance function model, which has a similar structure to the evolution equations in the newly proposed model in this study, behaves close to experimental results with loading conditions having $R=-1$.

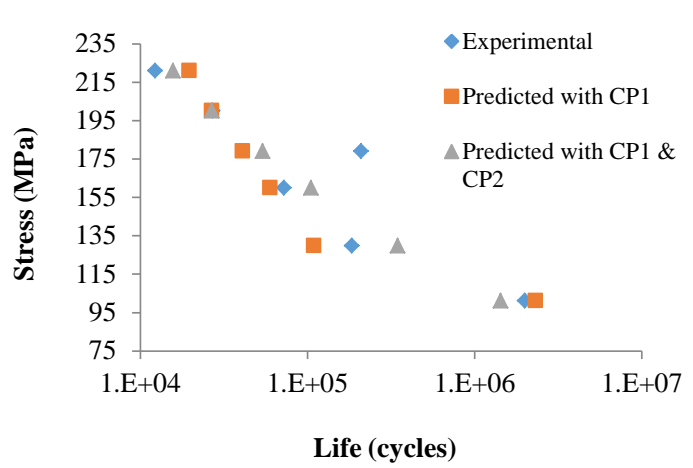

(a)

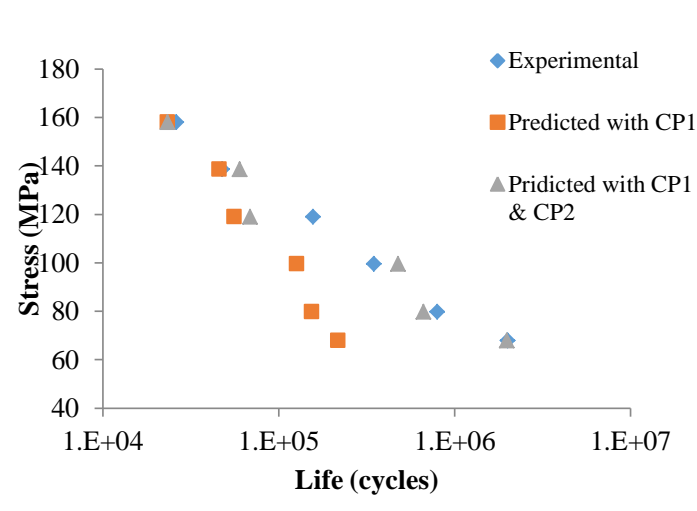

(c)

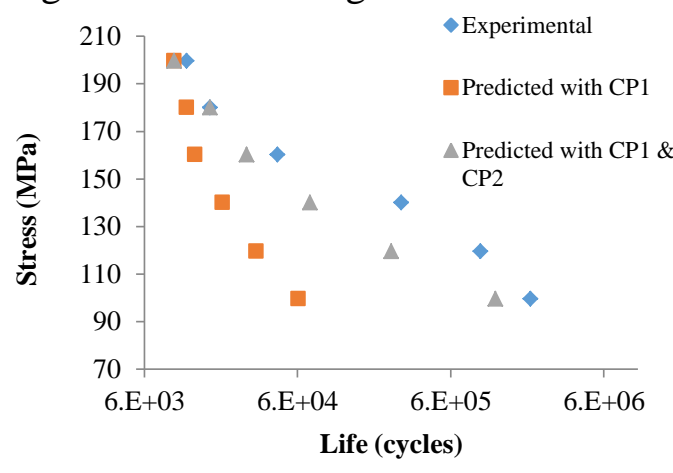

(b)

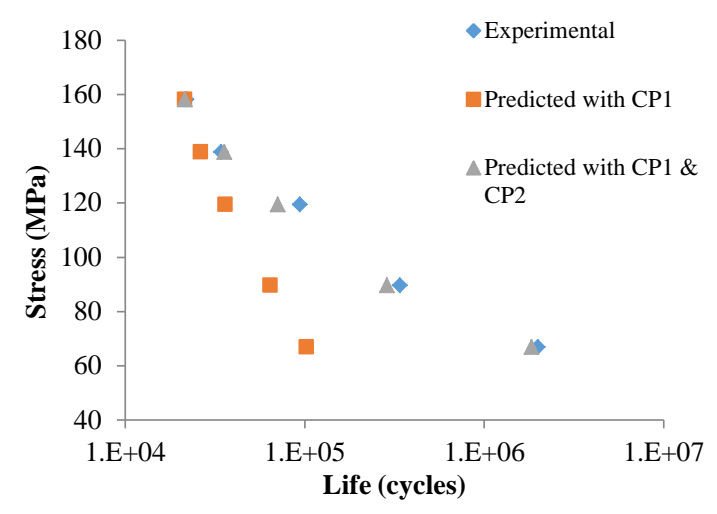

(d)

Figure 3. Predicted fatigue life (a) for $\mathrm{R}=-1$ and phase $=0^{\circ}$, (b) for $\mathrm{R}=-1$ and phase $=$ $90^{\circ}$, (c) $\mathrm{R}=0$ and phase $=0^{\circ}$, (d) $\mathrm{R}=0$ and phase $=90^{\circ}$.

Now for the cases of $R=0$ (positive mean) for both the phase $=0$ and phase $=90$ cases, the $\mathrm{CP}_{1}$ only case results in a diverging trend of fatigue life as we move away from the calibration point. The predicted life is on the conservative side but noticeably different from the experimental fatigue lives as we move from the low-cycle to highcycle region. Similarly, when we analyze the case with $\mathrm{CP}_{1}$ and $\mathrm{CP}_{2}$ we can see that the predicted fatigue life is in very good agreement with the experimental fatigue life, on the slightly conservative side, but it follows the trend of experimental life with appreciable accuracy, thus again showing the effectiveness of more than one calibration point for the proposed model. From the above results, the effectiveness of the proposed model is clearly shown in proportional as well as non-proportional loading cases. Also, the importance of more than one load point to calibrate the proposed model is highlighted. The application of GA to estimate the coefficients of the proposed mode equations includes an inherent flexibility to accommodate any kind of loading conditions. In this study we took the values of normal and shear stress to be the same, i.e. $\sigma \mathrm{a} / \tau \mathrm{a}=1$, which made the interpolation task for model coefficients relatively simple. In future studies the proposed model will be tested for cases with different load values for normal and shear 
stresses and also a methodology to interpolate the model coefficients in that case. Also, the proposed model will be tested against more complex loading conditions.

Table 3. Predicted fatigue life of C-40 steel.

\begin{tabular}{|c|c|c|c|}
\hline \multirow{2}{*}{$\begin{array}{c}\text { Normal and shear } \\
\text { stress at net area } \\
\left(\sigma_{\mathrm{a},} \tau_{\mathrm{a}}\right)(\mathrm{MPa})\end{array}$} & \multirow{2}{*}{$\begin{array}{l}\text { Experimental } \\
\text { cycles to failure } \\
\left(\mathrm{N}_{\mathrm{f}}\right) \times 10^{6}\end{array}$} & \multicolumn{2}{|c|}{ Predicted cycles to failure $\left(\mathrm{N}_{\mathrm{p}}\right) \times 10^{6}$} \\
\hline & & $\begin{array}{l}\text { One calibration } \\
\text { point }\left(\mathrm{CP}_{1}\right)\end{array}$ & $\begin{array}{c}\text { Two calibration } \\
\text { points }\left(\mathrm{CP}_{1} \& \mathrm{CP}_{2}\right)\end{array}$ \\
\hline \multicolumn{4}{|l|}{$\mathrm{R}=-1$ and phase $=0$} \\
\hline 101 & 2.0 & 2.32 & 1.43 \\
\hline 129.75 & 0.18 & 0.109 & 0.347 \\
\hline 159.92 & 0.072 & 0.06 & 0.105 \\
\hline 179 & 0.21 & 0.041 & 0.054 \\
\hline 200 & 0.027 & 0.0268 & 0.0268 \\
\hline 221 & 0.012 & 0.02 & 0.0157 \\
\hline \multicolumn{4}{|l|}{$\mathrm{R}=-1$ and phase $=90$} \\
\hline 99.6 & 2.0 & 0.06 & 1.182 \\
\hline 119.5 & 0.94 & 0.032 & 0.24 \\
\hline 140 & 0.285 & 0.02 & 0.072 \\
\hline 160.25 & 0.044 & 0.0128 & 0.028 \\
\hline 180 & 0.016 & 0.0113 & 0.016 \\
\hline 199.7 & 0.011 & 0.009 & 0.0094 \\
\hline \multicolumn{4}{|l|}{$\mathrm{R}=0$ and phase $=0$} \\
\hline 67.9 & 2.0 & 0.217 & 1.98 \\
\hline 79.72 & 0.79 & 0.15 & 0.664 \\
\hline 99.56 & 0.35 & 0.12 & 0.478 \\
\hline 119 & 0.157 & 0.056 & 0.069 \\
\hline 138.58 & 0.0477 & 0.046 & 0.06 \\
\hline 158.1 & 0.026 & 0.0234 & 0.023 \\
\hline \multicolumn{4}{|l|}{$\mathrm{R}=0$ and phase $=90$} \\
\hline 66.8 & 2.0 & 0.102 & 1.84 \\
\hline 89.55 & 0.34 & 0.064 & 0.287 \\
\hline 119.3 & 0.094 & 0.036 & 0.07 \\
\hline 138.75 & 0.034 & 0.026 & 0.036 \\
\hline 158.1 & 0.022 & 0.021 & 0.0215 \\
\hline
\end{tabular}

\section{CONCLUSIONS}

A new fatigue life estimation model has been proposed using the continuum mechanics concepts. Experimental fatigue lives for steel alloy C40 for in-phase and out-of-phase loading conditions are used to calibrate and analyze the accuracy of the proposed model. The new model predicted fatigue life with good agreement for in-phase and out-of-phase loads for zero mean and positive mean of loading stresses when two calibration points were used. But a diverging trend from experimental life was shown when moving away from the calibration point for the single calibration point case. Overall, the model has shown good accuracy and is simple to apply. A more detailed study is needed to examine 
the performance of the new model against more complex multiaxial and variable amplitude loading conditions.

\section{ACKNOWLEDGMENTS}

The authors would like to thank Universiti Malaysia Pahang for financial support under project no. RDU110332 and providing laboratory facilities.

\section{REFERENCES}

[1] Lee Y, Pan J, Hathaway R, Barkey M. Fatigue testing and analysis: Theory and practice. New York: Butterworth Heinemann; 2005.

[2] Stephens RI, Fatemi A, Stephens RR, Fuchs HO. Metal fatigue in engineering. New York: John Wiley and Sons, Inc.; 2000.

[3] Manson SS, Halford GR. Fatigue and durability of structural materials. Materials Park, Ohio: ASM International, Materials; 2006.

[4] Brighenti R, Carpinteri A. A notch multiaxial fatigue approach based on damage mechanics. International Journal of Fatigue. 2012;39:122-33.

[5] Kamal M, Rahman MM, Rahman AG. Fatigue life evaluation of suspension knuckle using multibody simulation technique. Journal of Mechanical Engineering and Sciences. 2012;3:291-300.

[6] Susmel L, Taylor D. The Modified Wohler Curve Method applied along with the Theory of Critical Distances to estimate finite life of notched components subjected to complex multiaxial loading paths. Fatigue and Fracture of Engineering Materials and Structures. 2008;31:1047-64.

[7] Kamal M, Rahman MM, Sani MSM. Application of multibody simulation for fatigue life estimation. International Journal of Automotive and Mechanical Engineering. 2013;7:912-23.

[8] Kamal M, Rahman MM. Fatigue life estimation models: A state of art. International Journal of Automotive and Mechanical Engineering. 2014;9:1599608.

[9] Kamal M, Rahman MM. Finite Element-Based Fatigue Behaviour of Springs in Automobile Suspension. International Journal of Automotive and Mechanical Engineering. 2014;10:1910-9.

[10] Macha E, Niesłony A. Critical plane fatigue life models of materials and structures under multiaxial stationary random loading: The state-of-the-art in Opole Research Centre CESTI and directions of future activities. International Journal of Fatigue. 2012;39:95-102.

[11] Atzori B, Berto F, Lazzarin P, Quaresimin M. Multi-axial fatigue behaviour of a severely notched carbon steel. International Journal of Fatigue. 2006;28:485-93.

[12] Susmel L, Taylor D. A critical distance/plane method to estimate finite life of notched components under variable amplitude uniaxial/multiaxial fatigue loading. International Journal of Fatigue. 2012;38:7-24.

[13] Susmel L, Tovo R. Estimating fatigue damage under variable amplitude multiaxial fatigue loading. Fatigue \& Fracture of Engineering Materials \& Structures. 2011;34:1053-77.

[14] Bishop NWM, Sherratt F. Finite element based fatigue calculations. Netherlands: NAFEMS Ltd.; 2000. 
[15] Rahman MM, Ariffin AK, Rejab MRM, Kadirgama K, Noor MM. Multiaxial fatigue behaviour of cylinder head for a free piston linear engine. Journal of Applied Sciences. 2009;9:2725-34.

[16] Fatemi A, Shamsaei N. Multiaxial fatigue: An overview and some approximation models for life estimation. International Journal of Fatigue. 2011;33:948-58.

[17] Rahman MM, Ariffin AK, Jamaludin N, Haron CHC. Vibration fatigue analysis of cylinder head of a new two-stroke free piston engine using finite element approach. Structural Integrity and Durability. 2005;1:121-9.

[18] Papuga J. A survey on evaluating the fatigue limit under multiaxial loading. International Journal of Fatigue. 2011;33:153-65.

[19] Ottosen NS, Stenstrom R, Ristinmaa M. Continuum approach to high-cycle fatigue modeling. International Journal of Fatigue. 2008;30:996-1006.

[20] Nieslony A, Ruzicka M, Papuga J, Hodr A, Balda M, Svoboda J. Fatigue life prediction for broad-band multiaxial loading with various PSD curve shapes. International Journal of Fatigue. 2012;44:74-88.

[21] Socie DF, Marquis GB. Multiaixal Fatigue. Warrendale, PA, USA: SAE; 2000.

[22] Brown MW, Miller KJ. Two decades of progress in the assessment of multiaxial low-cycle fatigue life. In: Amzallag C, Leis BN, Rabbe P, editors. Low-cycle fatigue and life prediction. West Conshohocken, PA: American Society for Testing and Materials. 1982; 482-99.

[23] Kandil FA, Brown MW, Miller KJ. Biaxial low-cycle fatigue fracture of 316 stainless steel at elevated temperatures. London: The Metals Society. 1982; 20310.

[24] Fatemi A, Socie DF. A critical plane approach to multiaxial fatigue damage including out of phase loading. Fatgiue and Fracture of Engineering Materials and Structures. 1988;11:149-66.

[25] Smith KN, Watson P, Topper TH. A Stress-Strain function for the fatigue of metals. Journal of Materials. 1970;5:767-78.

[26] Zhang $\mathrm{H}, \mathrm{Wu}$ Q, Lin J, Chen J, 124304. ZXAP. Thermal conductivity of polyethylene glycol nanofluids containing carbon coated metal nanoparticles. J Appl Phys. 2010;108:124304-9.

[27] Liu KC. A method based on virtual strain energy parameters for multiaxial fatigue life prediction. In: McDowell DL, Ellis R, editors. Advances in Multiaxial Fatigue. West Conshohocken, PA: American Society for Testing Materials; 1993; 67-84.

[28] Chu CC. Fatigue damage calculation using the critical plane approach. Journal of Engineering Materials and Technology. 1995;117:41-9.

[29] Manning R, Ewing, J. (2009). .RACQ Vehicles Technologies. Temperatures in cars survey. RACQ Vehicles Technologies. 2009:1-21.

[30] Davis L. Handbook of genetic algorithms. New York: Van Nostrand Reinhold; 1991.

[31] Whitely D. A genetic algorithm tutorial. Statistics and Computing. 1994;4:6585.

[32] Clarich A, Russo R, Carriglio M. Multi-objective optimization with modefrontier interfaces for ansa and metapost. 4th ANSA \& $\mu$ ETA International Conference. Thessaloniki, Greece; 2011.

[33] Perillo M, Primavera V, Fuligno L, Fabbri G, Steenbergen C, Pasini N. Optimization and robustness of complex material model simulations with 
modeFRONTIER. 7th European LS-DYNA Conference. Salzburg, Austria. 2009; 1-10.

[34] Franulovic M, Basan R, Prebil I. Genetic algorithm in material model parameters' identification for low-cycle fatigue. Computational Materials Science. 2009;45:505-10.

[35] Gantovnik VB, Anderson-Cook CM, Gürdal Z, Watson LT. A genetic algorithmwith memory for mixed discrete-continuous design optimization. Computer and Structures. 2003;81:2003-9.

[36] Brighenti R, Carpinteri A, Vantadori S. A genetic algorithm applied to optimisation of patch repairs for cracked plates. Computer Methods in Applied Mechanics and Engineering. 2006;196:466-75.

[37] Rahman MM, Kadirgama K, Noor MM, Rejab MRM, Kesulai SA. Fatigue life prediction of lower suspension arm using strain-life approach. European Journal of Scientific Research. 2009;30:437-50.

[38] Eitssayeam S, Intatha U, Rujijanagul G, Pengpat K, Tunkasiri T. Structural and electrical properties characterization of $(1-\mathrm{x}) \mathrm{PbZr} 0$. 52Ti0. $48 \mathrm{O}_{3}-\mathrm{xBaFe} 0$. 5Nb0. 5O 3 system. Applied Physics A. 2006;83:295-9.

[39] Technical Report on Low Cycle Fatigue Properties Ferrous and Non-Ferrous Materials. Society of Automotive Engineers; 2002.

[40] Atzori B, Berto F, Lazzarin P, Quaresimin M. Multi-axial fatigue behaviour of a severely notched carbon steel. International Journal of Fatigue. 2006;28:485-93.

[41] Brighenti R, Carpinteri A, Corbari N. Damage mechanics and Paris regime in fatigue life assessment of metals. International Journal of Pressure Vessels and Piping. 2013;104:57-68. 